\title{
Effect of SARS-CoV-2 pandemic induced lockdown on the aerosol loading over the coastal state, Goa
}

\author{
Atiba A. Shaikh, Avirup Sen and Harilal B. Menon* \\ School of Earth, Ocean and Atmospheric Sciences, Goa University, Goa 403 206, India
}

\begin{abstract}
The SARS-CoV-2 pandemic resulted in India imposing a nationwide lockdown on 22 March 2020, bringing all human activities to a complete halt. The current study focuses on the effect of lockdown on the abundance of atmospheric aerosols over Goa. The study focused on pre-lockdown, lockdown and period corresponding to lockdown in 2019. The AOD spectra depicted a decrease in the anthropogenically derived fine mode aerosols during the lockdown compared to the pre-lockdown period. Mean $\mathrm{AOD}_{500}$ for prelockdown and lockdown periods were $0.43 \pm 0.19$ and $0.53 \pm 0.11$ respectively. The higher $\mathrm{AOD}_{500}$ during lockdown was due to an increase in naturally derived coarse mode aerosols, which is further confirmed with the lower Ångström exponent values $(1.04 \pm 0.11)$. The mean black carbon mass concentration for the respective periods were $1990.45 \pm 470.87 \mathrm{ng} \mathrm{m}^{-3}$ and $1109.71 \pm 218.33 \mathrm{ng} \mathrm{m}^{-3}$, and the mean atmospheric forcing during the respective periods were $25.13 \pm$ $5.72 \mathrm{~W} \mathrm{~m}^{-2}, 27.31 \pm 3.71 \mathrm{~W} \mathrm{~m}^{-2}$ and $30.81 \pm 5.59 \mathrm{~W} \mathrm{~m}^{-2}$ respectively.
\end{abstract}

Keywords: Aerosol optical depth, radiative forcing, SARS-CoV-2.

\section{Introduction}

THE world went into lockdown amidst the spread of SARS-CoV-2 (COVID-19) after the World Health Organization declared it as a pandemic. A complete halt in human activities as a consequence of the lockdown led to a decrease in anthropogenic aerosols and thus a drastic improvement in air quality in otherwise polluted megacities of the world ${ }^{1}$. India went into a total lockdown on 22 March 2020. A complete halt of vehicular traffic and industrial activity resulted in a large decrease in ambient $\mathrm{PM}_{2.5}(43 \%)$ and $\mathrm{PM}_{10}(31 \%)$ aerosol concentrations during the lockdown period in comparison with previous years $^{2}$.

The composite aerosols (both natural and anthropogenic) prevailing over any region play an important role in the

\footnotetext{
*For correspondence. (e-mail: hbmenon@unigoa.ac.in)
}

Earth's radiation budget through their direct and indirect effects $^{3}$. The scattering (e.g. sea salt) and absorption (e.g. black carbon) by aerosols and the resultant cooling or heating are the direct effects whereas their role as cloud condensation nuclei is an indirect effect on Earth's radiation budget on a regional and global scale ${ }^{4}$. The anthropogenic fine mode aerosols released during incomplete combustion of fossil fuels, bio-fuels and waste incineration are extremely hazardous to human health and chronic exposure to them are known to cause various respiratory/ cardiovascular diseases 5 .

A study was conducted to understand the changes in aerosol characteristics over Goa during the lockdown period. It was carried out by analysing Aerosol Optical Depth (AOD) from $380 \mathrm{~nm}$ to $1025 \mathrm{~nm}$, Ångström exponent $(\alpha)$, Black Carbon (BC) mass concentration and satellite derived Tropospheric Vertical Column Density (TVCD) Nitrogen Dioxide $\left(\mathrm{NO}_{2}\right)$ during the lockdown period (22 March-20 April) and pre-lockdown period (20 February-21 March), i.e. a month prior to beginning of the countrywide lockdown. Similarly, the above analyses were carried out in 2019 during the period corresponding to lockdown. Generally, AOD across the wavelengths is high over Goa during the spring intermonsoon season (SIMS) (April-May) due to a large influx of aerosols from Western Asia ${ }^{6}$. It was also documented that a significant influx of continental aerosols during winter monsoon season (WMS) (DecemberMarch) is the result of prevailing north-east monsoon winds. However, the following summer monsoon season (SMS) (June-September) witnesses their removal due to incessant rains. The area is also dominated by coarse mode maritime aerosols in SIMS and SMS. Such a reversal of wind and the associated rain also bring down the concentration of $\mathrm{BC}$. The study further reveals that the highest concentration of $\mathrm{BC}\left(3.55 \mu \mathrm{g} \mathrm{m}^{-3}\right)$ encountered in WMS, decreased as the season advanced to SMS. It was reported that such a high $\mathrm{BC}$ accumulation over the area accounts for radiative forcing of $18.23 \mathrm{~W} \mathrm{~m}^{-2}$ during the pre-monsoon season (January-May) ${ }^{6,7}$.

Hence, the present study was carried out with an objective to understand the effect of COVID-19 induced lockdown on the composite aerosol dynamics and radiative forcing over Goa. 


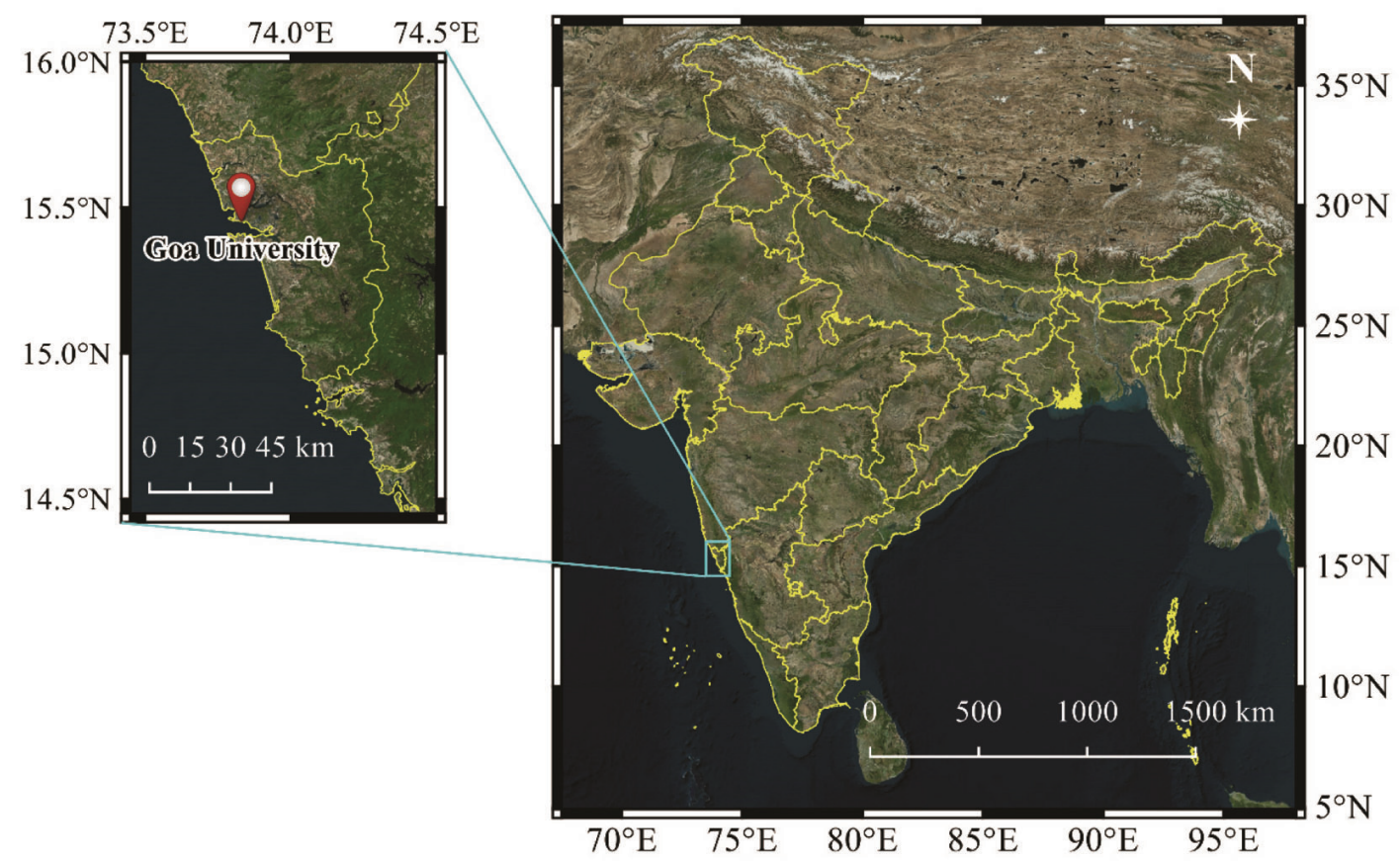

Figure 1. The study area (inset box) on the western coast.

\section{Study area}

Goa is a coastal state along the west coast of India (Figure 1), with the Arabian Sea on its west and the Western Ghats on the east. The orography affects the seasonally reversing winds, that in turn govern the aerosol dynamics in the region. The study period covers the end of the WMS and beginning of SIMS. During WMS, the northerly to north-easterlies flow from the continent, leading to enhanced anthropogenically derived aerosol over the area. Being in the vicinity of coastal waters, the study area is also subjected to land and sea breeze, which has also been accounted while analysing aerosol dynamics in the region. The in-situ observations were carried out at Goa University $\left(15.46^{\circ} \mathrm{N}\right.$ and $\left.73.83^{\circ} \mathrm{E}\right)$.

\section{Data and methodology}

\section{Aerosol optical depth}

AOD was estimated using Microtops II Sunphotometer during the lockdown (2020) and period corresponding to lockdown in 2019 whereas the same was estimated during the pre-lockdown period of 2020 using Multi Wavelength Radiometer (MWR).

Microtops II Sunphotometer. Microtops II Sunphotometer (Solar Light Co, USA) is a multi-wavelength handheld instrument with five wavelength bands at 380, 440, 500, 675 and $1020 \mathrm{~nm}$. The instrument works on the principle of Beer-Lambert law. It has a field view of $2.5^{\circ}$. The solar flux is used as the light source by the instrument and AODs are computed using internal calibration coefficients. The location details obtained by Global Positioning System (GPS) is fed to the instrument ${ }^{8}$. The observations and analysis were carried out using the standard protocol given elsewhere ${ }^{9}$.

Multi wavelength radiometer. AODs at ten wavelengths of $380,400,450,500,600,650,750,850,935$ and $1025 \mathrm{~nm}$ were estimated from MWR measured values obtained with a field view of $\sim 2.1^{\circ}$. It also works on the principle of the Beer-Lambert law and makes continuous measurements of direct solar radiation throughout the day. The spectral AOD is estimated using Langley plot method. Details of AOD estimation from MWR is available elsewhere ${ }^{10}$.

Angström exponent. Ångström exponent $(\alpha)$ is estimated from the spectral AOD for the given range of $380 \mathrm{~nm}$ to $1025 \mathrm{~nm}$ using Ångström power law ${ }^{11}$

$$
\tau_{\lambda}=\beta \lambda^{-\alpha},
$$

where $\alpha$ is the wavelength exponent indicating the size distribution of aerosols and $\beta$ is the turbidity parameter.

\section{Black carbon mass concentration}

$\mathrm{BC}$ is an absorbing aerosol species. BC mass concentrations were estimated using a seven channel (370, 470, 
520, 590, 660, 880 and $950 \mathrm{~nm}$ ) Aethalometer (model AE-42), a self-contained, automatic instrument. BC mass concentration is estimated from absorbance at $880 \mathrm{~nm}$ using the filtration on quartz fibre and optical transmission techniques $^{12}$. The instrument was operated continuously at every 5 minutes interval with 2.5 litre per minute (lpm) flow rate.

\section{Nitrogen dioxide}

Level-3 daily global gridded $\left(0.25 \times 0.25^{\circ}\right)$ data of Total Tropospheric Column $\mathrm{NO}_{2}(\mathrm{OMNO} 2 \mathrm{~d})$ were retrieved from the Ozone Monitoring Instrument (OMI) ${ }^{13}$. In L2G Giovanni, $\mathrm{NO}_{2}$ data are provided only for near clear sky (cloud radiance fraction is less than 30\%) (https:// giovanni.gsfc.nasa.gov/giovanni/) conditions.

\section{Meteorological parameters}

To compute the wind vector and analyse its pattern, European Centre for Medium Range Weather Forecasts (ECMWF) ERA5 reanalysis 6 hourly data of $u$ and $v$ components of surface wind were obtained over the study area $^{14}$. In addition, 6 hourly ERA5 reanalysis data of divergence $\left(\mathrm{s}^{-1}\right)$ at $1000 \mathrm{hPa}$ pressure level were obtained (https://cds.climate.copernicus.eu/cdsapp $\{\#\} ! /$ home).

\section{HYSPLIT back trajectories}

Air mass back trajectories were computed using National Oceanic and Atmospheric Administration-Air Resources Laboratory (NOAA-ARL) Hybrid Single Particle Lagrangian Integrated Trajectory (HYSPLIT, version 4) model (http://ready.arl.noaa.gov/HYSPLIT.php) ${ }^{15,16}$. The model is provided with NCEP Global Data Assimilation System (GDAS) meteorological data obtained from meteorological data archives of NOAA-ARL (ftp://arlftp. arlhq.noaa.gov/pub/archives/gdas1). To identify the source of air parcel, 120 hours back trajectories were computed at three different heights, i.e. 500, 1500 and 3000 meters above ground level (m.a.g.l). The daily Planetary Boundary Layer (PBL) heights were also estimated from HYSPLIT model.

\section{Aerosol radiative forcing}

The daily aerosol radiative forcing (ARF) for shortwave radiation was estimated using Santa Barbara DISORT Atmospheric Radiative Transfer model, SBDART 4.36 (ref. 17). The model uses daily $\mathrm{AOD}_{500}$ and PBL height as input along with details of location and time. A polluted marine aerosol model was considered. The other inputs for ARF are solar zenith angle and AOD due to BC $\left(\mathrm{AOD}_{\mathrm{BC}}\right)$. Along with these variables, additional inputs are atmospheric profile (tropical), background gas concentration for $\mathrm{CO}_{2}, \mathrm{~N}_{2} \mathrm{O}$, and $\mathrm{CH}_{4}$ for 2019 and 2020, background troposphere (rural) and surface albedo model (vegetation). The varying components of RF between prelockdown and lockdown periods are AODs due to mineral dust, sulphate aerosols and BC. Though the results show an increasing pattern of coarse mode particles during the lockdown period, only the effect of varying $\mathrm{BC}$ has been incorporated while computing RF of both the periods and the contributions due to the other constituents were assumed constant, which need not be strictly the case. $\mathrm{AOD}_{\mathrm{BC}}$ was estimated using the following formula $^{18}$

$$
\left(\frac{\mathrm{BC} \text { mass conc. }}{1000} / 0.0000599\right) \times 0.0000006385 \times \mathrm{PBL} .
$$

It computes radiative flux at top of atmosphere (TOA) and surface (SFC) with and without aerosol. Net forcing at the TOA and SFC is computed as

$$
\begin{aligned}
\mathrm{ARF}_{\mathrm{TOA} / \mathrm{SFC}} & =\text { flux }(\mathrm{NET})_{\text {aerTOA/SFC }} \\
& - \text { flux }(\mathrm{NET})_{\text {noaerTOA/SFC }}
\end{aligned}
$$

and atmospheric (ATM) forcing is

$$
\mathrm{ARF}_{\mathrm{ATM}}=\mathrm{ARF}_{\mathrm{TOA}}-\mathrm{ARF}_{\mathrm{SFC}} .
$$

\section{Results and discussion}

To analyse the gradual variation of aerosol characteristics in response to the lockdown, the period of lockdown in 2020 was divided into three sections of ten days each, viz. P7 (22 March-31 March), P8 (1 April-10 April), and P9 (11 April-20 April). The same criteria has been adopted to study the pre-lockdown period and therefore, divided into three sections, viz. P4 (20 February-1 March), P5 (2 March-11 March), P6 (12 March-21 March). Furthermore the corresponding days to the period of lockdown was studied in 2019 and was divided into P1 (22 March-31 March), P2 (1 April-10 April) and P3 (11 April-20 April).

\section{Prevailing meteorology}

Predominantly a strong convergence zone was seen over Goa during P4 (Figure $2 d$ ) in the pre-lockdown period, whereas a weak zone of convergence over Goa with divergence zones running parallel to the coastline and Western Ghats were observed during P5 and P6 (Figures $2 e$ and $f$ ). A strong divergence zone was seen around Goa during P5, whereas it was absent along the Western Ghats during P4. This is also evident from the wind vectors as shown in Figure $2 d-f$. Mean wind speeds over 

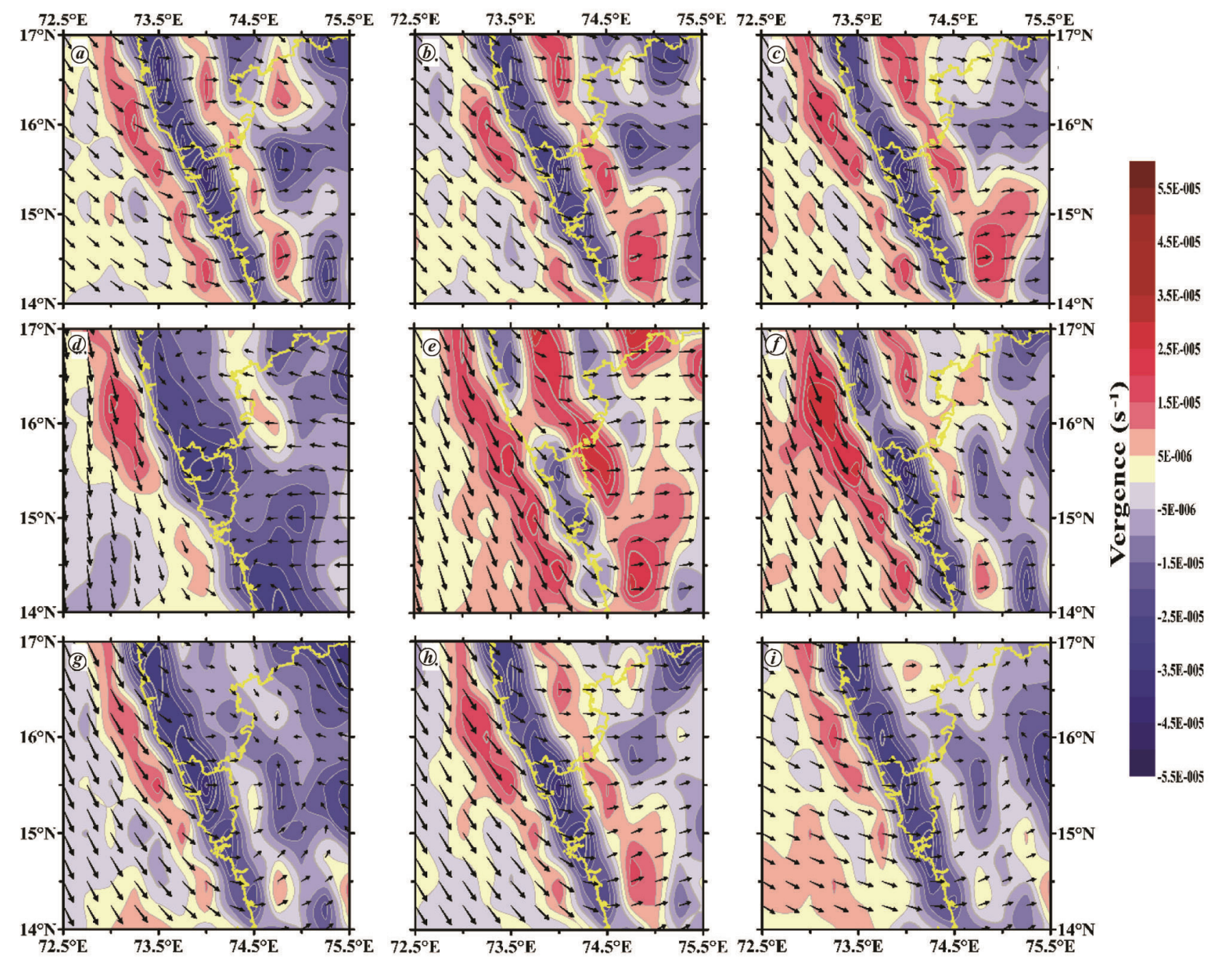

Figure 2. Synoptic observations of divergence $\left(\mathrm{s}^{-1}\right)$ at $1000 \mathrm{hPa}$ and surface winds $\left(\mathrm{ms}^{-1}\right)$ over the study area during (a) $\mathrm{P} 1,(\boldsymbol{b}) \mathrm{P} 2,(\boldsymbol{c}) \mathrm{P} 3,(\boldsymbol{d}) \mathrm{P} 4$, (e) $\mathrm{P} 5,(\boldsymbol{f}) \mathrm{P} 6,(\boldsymbol{g}) \mathrm{P} 7,(\boldsymbol{h}) \mathrm{P} 8,(\boldsymbol{i}) \mathrm{P} 9$.

Goa during the pre-lockdown were in the range $0.3-$ $3.5 \mathrm{~ms}^{-1}$. Highest wind speeds over Goa and adjoining Arabian Sea were $3.5 \mathrm{~ms}^{-1}$ and $5.5 \mathrm{~ms}^{-1}$ respectively during P6 (Figure $2 f$ ), whereas the lowest wind speed of $0.3 \mathrm{~ms}^{-1}$ was observed during P4 (Figure $2 d$ ) over Goa. In the lockdown period, though convergence zones were prevailing over Goa, the divergence zones were absent along the Western Ghats during P7 and P9, with weak divergence zones over entire eastern Arabian Sea (Figure $2 \mathrm{~g}-i$ ). Average wind speeds ranged from 0.8 to $2.3 \mathrm{~ms}^{-1}$, with lowest wind speeds of 0.8 and $0.9 \mathrm{~ms}^{-1}$ in P7 and P9 respectively over Goa. In 2019, similar convergence zones were seen over Goa with divergence zones running along the coast and Western Ghats throughout the study period, with average wind speeds in the range $1.3-2.5 \mathrm{~ms}^{-1}$.

\section{Spectral AOD and Angström exponent}

In general, high aerosol concentrations were observed over the western coast of India during February to
April $^{7,19,20}$, owing to the transport of aerosols from the Arabian region and arid regions of north-western India ${ }^{21}$ (Figure 3).

Figure $4 a$ shows the temporal variability of AOD spectra from P1 to P9. As expected, the spectral distribution of AOD displayed large variability between the prelockdown and lockdown periods. During the lockdown period, the spectrum was more flattened compared to the pre-lockdown period, where the spectrum was steeper due to higher AOD values at shorter wavelengths. The AOD varied considerably from $1.02 \pm 0.45$ and $0.81 \pm$ 0.16 at $380 \mathrm{~nm}$ to $0.15 \pm 0.10(1025 \mathrm{~nm})$ and $0.29 \pm 0.08$ $(1020 \mathrm{~nm})$ during pre-lockdown and lockdown period respectively (Figure $4 \mathrm{~b}$ ). The steeper spectra during the pre-lockdown period with mean $\alpha$ value of $1.76 \pm 0.64$ (Figure $4 c$ ), indicate the effect of anthropogenic aerosols (fine mode) over the region ${ }^{22}$. The decrease in $\alpha$ from $1.36 \pm 0.05$ in $\mathrm{P} 7$ to $0.96 \pm 0.08$ in $\mathrm{P} 8$, and even further to $0.79 \pm 0.20$ in P9, indicates a decrease in the influence of anthropogenic aerosols during the lockdown period. 


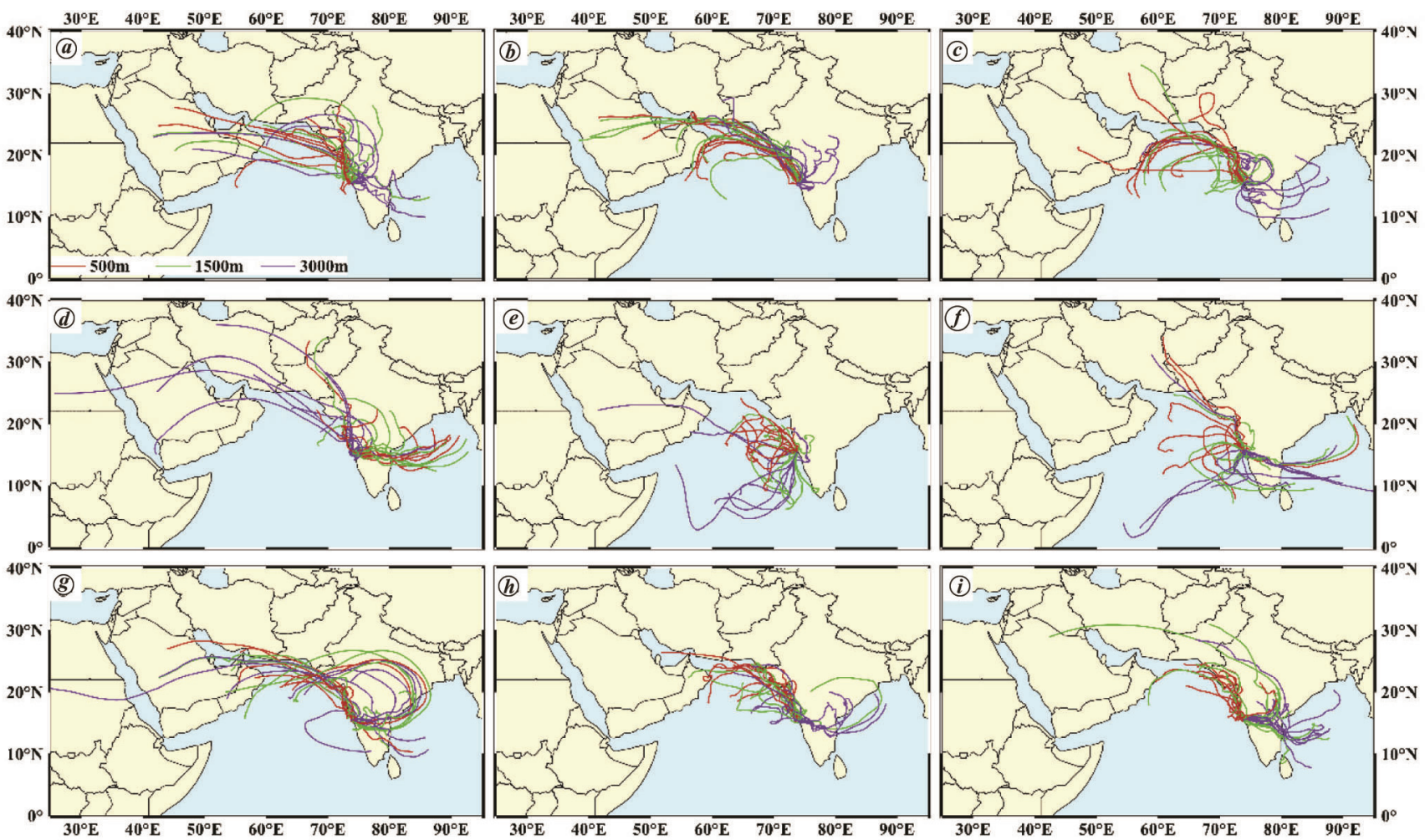

Figure 3. $120 \mathrm{~h}$ air-mass back trajectories culminating over Goa at heights of 500 (red), 1500 (green) and 3000 (purple) m.a.g.l for (a) P1, (b) P2, (c) $\mathrm{P} 3,(d) \mathrm{P} 4,($ e $) \mathrm{P} 5,(f) \mathrm{P} 6,(\boldsymbol{g}) \mathrm{P} 7,(\boldsymbol{h}) \mathrm{P} 8,(\boldsymbol{i}) \mathrm{P} 9$.

The $\mathrm{AOD}_{500}$ was high during $\mathrm{P} 9(0.57 \pm 0.18)$ over Goa, a result of advected coarse mode maritime aerosols. This is evident from the spatial distribution of convergence pattern, wherein the westerlies were strong during P6-P8 and subsequently became weak during P9. This means that the strong winds during the initial phase advected maritime aerosols and an increase in the residence time of the aerosols due to the weak winds $\left(0.9-0.18 \mathrm{~ms}^{-1}\right)$ lead to higher $\mathrm{AOD}_{500}$ during P9 $\left(0.9-0.18 \mathrm{~ms}^{-1}\right)^{7,23}$. In studies $^{7,20,24}$ it was stated that high AOD and low $\alpha$ values correspond to coarse mode aerosols. Long range transport of mineral dust from Arabian or western Indian regions ${ }^{6,7,21}$, along with transported aerosols from the semiarid Deccan region, also add to the aerosol loading over Goa (Figure $3 g-i$ ). Periods having spatially distributed convergence zones (Figure $2 d, g$ and $i$ ) showed higher values of AOD, as winds from different regions transporting aerosol laden air masses are brought over the study area due to formation of a convergence at the surface. During the entire period of lockdown, the strength of the low level convergence was vivid from the signature of convergence observed at $700 \mathrm{hPa}$. However, weakening of the convergence at this level during the latter phase (P8, P9) of the lockdown further acts as the mechanism to increase the residence time of aerosols, as observed from the high AOD values.
According to Menon et al. ${ }^{6}$ peak values of columnar AOD are observed over Goa in March-April, wherein April is dominated by maritime aerosol. To further comprehend the effects of lockdown on the aerosols in the region, spectral AOD during the lockdown period in 2020 was compared to that of 2019 for the same period.

The AOD displayed a flattened spectra for both years, except the magnitude of AOD at all wavelengths was higher during 2019, with the highest AOD recorded during P1. The mean $\alpha$ value for the period in 2019 was $1.06 \pm 0.24$, indicating optical complexity of the atmosphere due to a mix of maritime coarse mode and continentally advected fine mode aerosols ${ }^{8}$. Lower $\alpha$ values during P8 $(0.96 \pm 0.08)$ and P9 $(0.79 \pm 0.20)$ in 2020 , indicate that the atmosphere over the region was dominated by maritime and dust aerosols.

\section{Black carbon mass concentration and nitrogen dioxide}

The mean $\mathrm{BC}$ mass concentration for the pre-lockdown period was $1990.45 \pm 470.87 \mathrm{ng} \mathrm{m}^{-3}$ (Figure $5 a$ ) with highest BC mass concentration during P4 (3064.27 \pm $323.12 \mathrm{ng} \mathrm{m}^{-3}$ ). The $\mathrm{BC}$ mass concentration decreased during the lockdown period $\left(1109.71 \pm 218.83 \mathrm{ng} \mathrm{m}^{-3}\right)$ 
due to a complete halt in anthropogenic activities. The $\mathrm{BC}$ mass concentration were high during P4, P5 and P6 owing to the north-east monsoon, leading to predominant continental aerosols over $\mathrm{Goa}^{7}$. The $\mathrm{BC}$ mass concentration was also higher in $2019\left(1236.36 \pm 556.72 \mathrm{ng} \mathrm{m}^{-3}\right)$ compared to lockdown in 2020. The higher standard deviation in 2019 compared to 2020 shows that the BC originated from multiple sources.

It is essential to study $\mathrm{NO}_{2}$ as it is released mainly from anthropogenic activities and undergoes gas to particle conversion to form nitrate aerosols. The mean $\mathrm{NO}_{2}$ TVCD was $0.77 \times 10^{15} \pm 0.31 \times 10^{15}$ molecules $\mathrm{cm}^{-2}$ (Figure $5 \mathrm{~b}$ ) for the pre-lockdown period and was $0.77 \times$ $10^{15} \pm 0.22 \times 10^{15}$ molecules $\mathrm{cm}^{-2}$ with highest $\mathrm{NO}_{2}$ TVCD in P7 $\left(1.16 \times 10^{15} \pm 0.34 \times 10^{15}\right.$ molecules $\left.\mathrm{cm}^{-2}\right)$. Higher values during P7 may be a result of the continental derived $\mathrm{NO}_{2}$ (Figure $3 \mathrm{~g}$ ). Even though the winds were from the continent during P9 (Figure $4 b$ ), the lower $\mathrm{NO}_{2}$ TVCD during this period was a consequence of the halt in anthropogenic activities during the lockdown. Similarly, higher values of $\mathrm{NO}_{2}$ TVCD were seen during P4 $\left(1.08 \times 10^{15} \pm 0.40 \times 10^{15}\right.$ molecules $\left.\mathrm{cm}^{2}\right)$, when the winds were blowing from the continent (Figure $3 d$ ). Lower $\mathrm{NO}_{2}$ TVCD was seen during P5 $(0.58 \times$ $10^{15} \pm 0.34 \times 10^{15}$ molecules $\left.\mathrm{cm}^{-2}\right)$ and P6 $(0.66 \times$
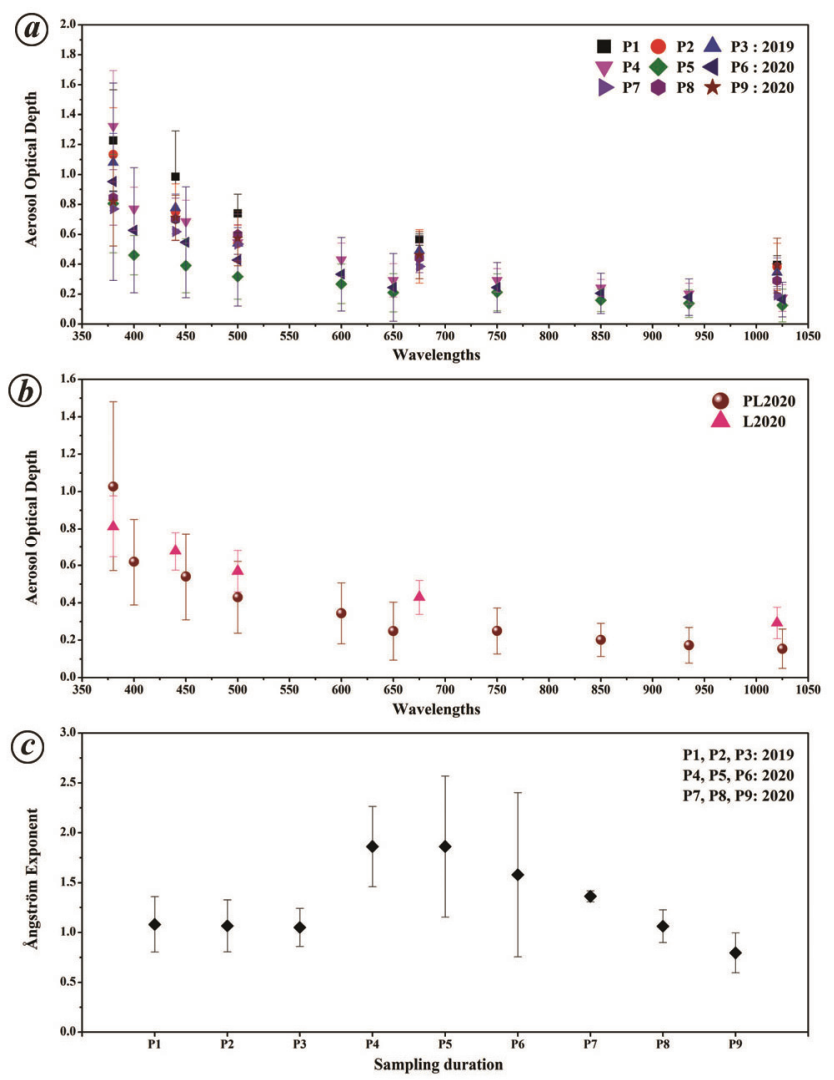

Figure 4. $\boldsymbol{a}$, Spectral variation of AOD during the study period. $\boldsymbol{b}$, AOD spectra for the pre-lockdown (PL) and lockdown (L) periods. $c$ Size distribution (Ångström exponent) during the study period.
$10^{15} \pm 0.18 \times 10^{15}$ molecules $\mathrm{cm}^{-2}$ ) as the winds were of oceanic origin (Figure $3 e$ and $f$ ) and also, higher wind speeds during the period may have led to dispersion of gas. The $\mathrm{NO}_{2}$ TVCD was higher in $2019(0.94 \times$ $10^{15} \pm 0.20 \times 10^{15}$ molecules $\mathrm{cm}^{-2}$ ).

\section{Direct aerosol shortwave radiative forcing (DASRF)}

The DASRF over Goa during the periods of study was estimated. Composite $\mathrm{AOD}_{500}$ was higher during the

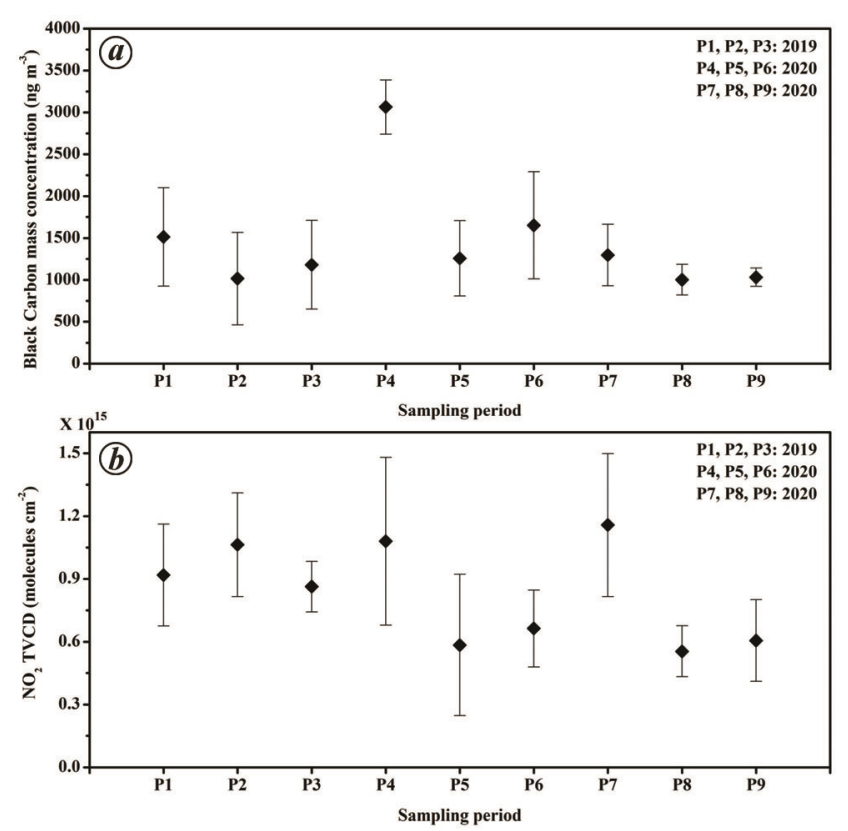

Figure 5. $\boldsymbol{a}$, Black carbon mass concentrations $\left(\mathrm{ng} \mathrm{m}^{-3}\right), \boldsymbol{b}, \mathrm{NO}_{2}$ TVDC (molecules $\mathrm{cm}^{-2}$ ) during the study period.

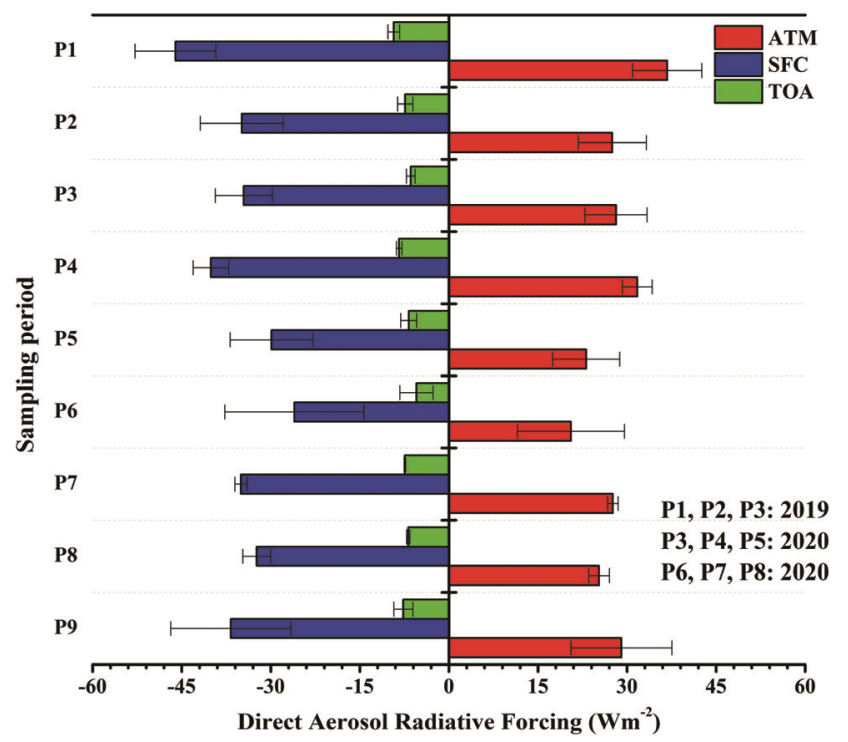

Figure 6. Direct Aerosol Radiative Forcing $\left(\mathrm{W} \mathrm{m}^{-2}\right)$ at TOA, SFC and ATM during the study period. 
lockdown period. However, as higher BC mass concentrations were recorded at the site during the pre-lockdown period, consequently the $\mathrm{AOD}_{\mathrm{BC}}$ was also higher compared to the lockdown period. Therefore, DASRF computations during the lockdown period were made by the model with a lower weightage given to $\mathrm{AOD}_{\mathrm{BC}}$.

The mean TOA forcing over Goa was $-6.87 \pm$ $1.54 \mathrm{~W} \mathrm{~m}^{-2}$ and $-7.33 \pm 0.67 \mathrm{~W} \mathrm{~m}^{-2}$ during pre-lockdown and lockdown periods in 2020 respectively, and the corresponding mean surface forcing was $-32.00 \pm 7.29 \mathrm{~W} \mathrm{~m}^{-2}$ and $-34.71 \pm 4.48 \mathrm{~W} \mathrm{~m}^{-2}$. Both TOA forcing and surface forcing were higher in the lockdown period than the prelock down period of 2020 (Figure 6). The mean atmospheric forcing for the respective pre-lockdown and lockdown periods were $25.13 \pm 5.72$ and $27.31 \pm 3.71 \mathrm{~W} \mathrm{~m}^{-2}$. The highest atmospheric forcing was observed during P9 $\left(29.05 \pm 8.50 \mathrm{~W} \mathrm{~m}^{-2}\right)$ in 2020 owing to the high AOD. The mean TOA forcing and surface forcing for corresponding period in 2019 were $-7.69 \pm 0.99$ and $-38.49 \pm$ $6.19 \mathrm{~W} \mathrm{~m}^{-2}$ respectively. The resultant mean atmospheric forcing was $30.81 \pm 5.59 \mathrm{~W} \mathrm{~m}^{-2}$. The highest atmospheric forcing was seen during P1 $\left(36.76 \pm 8.50 \mathrm{~W} \mathrm{~m}^{-2}\right)$ in 2019 as the highest AOD was observed during P1 (Figure $4 a$ ).

\section{Conclusions}

- The mean AOD during the pre-lockdown period varied considerably from $1.02 \pm 0.45(380 \mathrm{~nm})$ to $0.15 \pm 0.10(1025 \mathrm{~nm})$ and in the lockdown period it ranged from $0.81 \pm 0.16(380 \mathrm{~nm})$ to $0.29 \pm 0.08$ $(1020 \mathrm{~nm})$. This indicates a decrease in the fine mode aerosols and the dominance of naturally derived coarse mode aerosols during this period.

- Lower $\alpha$ values $(0.79 \pm 0.20)$ and high AOD observed during the final phase of lockdown support the fact that the atmosphere was dominated by naturally produced coarse mode aerosols (maritime and dust). The mean $\alpha$ values $(1.76 \pm 0.64)$ during the pre-lockdown period depict an optically complex atmosphere with influence of anthropogenically derived aerosols.

- Despite the observations being made during lockdown or non-lockdown periods, a convergence zone is the predominant feature in the study area. During the prelockdown period, divergence zones run adjacent to the coastline and along Western Ghats. However, during lockdown period, the convergence zone spreads more spatially, thus weakening the divergence zone along the Western Ghats during this period.

- High aerosol loading encountered during the lockdown is attributed to the spatial extent of convergence zone and irregular pattern of average wind speeds. Higher wind speeds during the first phase of lockdown advected natural aerosols from coastal waters, western Indian regions and from the semi-arid Deccan plateau. However, the weak winds during the final phase of lockdown (last ten days) increased the residence time of aerosols and subsequent increase in ambient aerosols.

- The BC mass concentration decreased over Goa during lockdown period as compared to pre-lockdown by $881 \mathrm{ng} \mathrm{m}^{-3}$.

- The mean TOA forcing was $-6.87 \pm 1.54 \mathrm{~W} \mathrm{~m}^{-2}$, $-7.33 \pm 0.67 \mathrm{~W} \mathrm{~m}^{-2}$ and $-7.69 \pm 0.99 \mathrm{~W} \mathrm{~m}^{-2}$ during pre-lockdown and lockdown period in 2020 and the period corresponding to the lockdown in 2019 respectively. The SFC forcing was $-32.00 \pm 7.29 \mathrm{~W} \mathrm{~m}^{-2}$, $-34.71 \pm 4.48 \mathrm{~W} \mathrm{~m}^{-2}$ and $-38.49 \pm 6.19 \mathrm{~W} \mathrm{~m}^{-2}$ during the aforementioned periods.

- The resultant mean ATM forcing for the respective periods was $25.13 \pm 5.72,27.31 \pm 3.71 \mathrm{~W} \mathrm{~m}^{-2}$ and $30.81 \pm 5.59 \mathrm{~W} \mathrm{~m}^{-2}$.

1. Zambrano-monserrate, M. A., Alejandra, M. and Sanchez-alcalde, L., Science of the total environment indirect effects of COVID-19 on the environment. Sci. Total Environ., 2020, 728, 138813.

2. Sharma, S., Zhang, M., Anshika, Gao, J., Zhang, H. and Kota, S. H., Effect of restricted emissions during COVID-19 on air quality in India. Sci. Total Environ., 2020, 728, 138878.

3. Charlson, R. J. et al., Climate forcing by anthropogenic aerosols. Science, 1992, 255, 423-430.

4. Ramanathan, V., Crutzen, P. J., Kiehl, J. T. and Rosenfeld, D., Aerosols, climate, and the hydrological cycle. Science, 2001, 294, 2119-2124.

5. Pope III, C. A. and Dockery, D. W., Health effects of fine particulate air pollution: lines that connect health effects of fine particulate air pollution: lines that connect. J. Air Waste Manage. Assoc., 2006, 56, 709-742.

6. Shirodkar, S. and Menon, H. B., Aerosol optical properties over a coastal site in Goa, along the west coast of India. J. Atmos. SolarTerrestrial Phys., 2015, 130, 182-189.

7. Menon, H. B., Shirodkar, S., Kedia, S., Ramachandran, S., Babu, S. and Moorthy, K. K., Temporal variation of aerosol optical depth and associated shortwave radiative forcing over a coastal site along the west coast of India. Sci. Total Environ., 2014, 468, 83-92.

8. Morys, M. et al., Design, calibration, and performance of MICROTOPS II handheld ozone monitor and Sun photometer. J. Geophys. Res. Atmos., 2001, 106, 14573-14582.

9. Frouin, R. et al., Sun and sky radiance measurements and data analysis protocols. NASA/TM-2003-21621/Rev-Vol III, 60, 2003.

10. Krishna Moorthy, K., Satheesh, S. K. and Krishna Murthy, B. V., Investigations of marine aerosols over the tropical Indian Ocean. J. Geophys. Res. Atmos., 1997, 102, 18827-18842.

11. Angström, A., Techniques of determining the turbidity of the atmosphere. Tellus, 1961, 13, 214-223.

12. Hansen, A. D. A., Rosen, H. and Novakov, T., The aethalometeran instrument for the real-time measurement of optical absorption by aerosol particles. Sci. Total Environ., 1984, 36, 191-196.

13. Levelt, P. F. et al., Science objectives of the ozone monitoring instrument. IEEE Trans. Geosci. Remote Sens., 2006, 44, 11991208.

14. Hellerman, S. and Rosenstein, M., Normal monthly wind stress over the world ocean with error estimates. J. Phys. Oceanogr., 1983, 13, 1093-1104.

15. Draxler, R. R. and Hess, G. D., Description of the HYSPLIT_4 Modeling System. NOAA Technical Memorandum ERL ARL224, NOAA Air Resour. Lab. Silver Spring, MD, 2004, p. 28. 
16. Stein, A. F., Draxler, R. R., Rolph, G. D., Stunder, B. J. B., Cohen, M. D. and Ngan, F., NOAA's HYSPLIT atmospheric transport and dispersion modeling system. Bull. Am. Meteorol. Soc., 2015, 96, 2059-2077.

17. Ricchiazzi, P., Yang, S., Gautier, C. and Sowle, D., SBDART: A research and teaching software tool for plane-parallel radiative transfer in the earth's atmosphere. Bull. Am. Meteorol. Soc., 1998, 79, 2101-2114.

18. Hess, M., Koepke, P. and Schult, I., Optical properties of aerosols and clouds: The software package OPAC. Bull. Am. Meteorol. Soc., 1998, 79, 831-844.

19. Nair, S. K., Rajeev, K. and Parameswaran, K., Wintertime regional aerosol distribution and the influence of continental transport over Indian Ocean. J. Atmos. Solar-Terrestrial Phys., 2003, 65, 149-165.

20. Moorthy, K. K. et al., Wintertime spatial characteristics of boundary layer aerosols over peninsular India. J. Geophys. Res. D Atmos., 2005, 110, 1-11.

21. Moorthy, K. K., Satheesh, S. K., Babu, S. S. and Dutt, C. B. S., Integrated campaign for aerosols, gases and radiation budget (ICARB): an overview. J. Earth Syst. Sci., 2008, 117, 243-262.
22. Eck, T. F. et al., Wavelength dependence of the optical depth of biomass burning, urban, and desert dust aerosols. J. Geophys. Res. Atmos., 1999, 104, 31333-31349.

23. Toledano, C. et al., Aerosol optical depth and Ångström exponent climatology at El Arenosillo AERONET site (Huelva, Spain). $Q$. J. R. Meteorol. Soc. A J. Atmos. Sci. Appl. Meteorol. Phys. Oceanogr., 2007, 133, 795-807.

24. Gogoi, M. M., Suresh Babu, S., Krishna Moorthy, K., Manoj, M. R. and Chaubey, J. P., Absorption characteristics of aerosols over the northwestern region of India: Distinct seasonal signatures of biomass burning aerosols and mineral dust. Atmos. Environ., 2013, 73, 92-102.

ACKNOWLEDGEMENTS. We thank the Indian Space Research Organisation (ISRO) for providing funds under Aerosol Radiative Forcing over India (ARFI-IGBP). We are grateful to the Vice Chancellor of Goa University for the facilities provided on campus. The first two authors thank our fellow researchers Mr Partha Patil and Dr Arjun Adhikari for the help and support during the work.

doi: $10.18520 / \mathrm{cs} / \mathrm{v} 120 / \mathrm{i} 2 / 360-367$ 